\section{WHY IS FREEDOM FROM ATRIAL FIBRILLATION STILL LOWER WITH ENDOSCOPIC PULMONARY VEIN ISOLATION THAN WITH THE COX MAZE III PROCEDURE?}

To the Editor:

We read with great interest the recent article by Yilmaz and coworkers. ${ }^{1}$ We have some brief comments. Since its first description in the Journal in 1991 by Cox and colleagues, the Cox maze procedure and its subsequent modifications have been the most frequently used option for patients with intractable supraventricular arrhythmias, with the results heavily scrutinized. Although reported results have varied somewhat, long-term success (freedom from atrial fibrillation $[\mathrm{AF}]$ recurrence) rates as high as $96 \%$ have been reported. ${ }^{2}$ Despite its remarkable success, the procedure has not been widely adopted by surgeons or cardiologists, in part because of its complexity and technical difficulty. As a result, only a few surgeons have gained sufficient experience, and many have waited for less-invasive or simpler approaches to treat those extremely common arrhythmias. With modern and less invasive technologies, Yilmaz and coworkers ${ }^{1}$ reported for the first time a completely endoscopic approach. In their experience, $78 \%$ of patients remained free from $\mathrm{AF}$ recurrence at a mean follow-up of 9 months. The reasons for this lower rate of success are unclear. Among potential mechanisms, one

\footnotetext{
The Editor welcomes submissions for possible publication in the Letters to the Editor section that consist of commentary on an article published in the Journal or other relevant issues. Authors should: • Include no more than 500 words of text, three authors, and five references. - Type with double-spacing. - See http://jtcs.ctsnetjournals.org/misc/ifora.shtml for detailed submission instructions. - Submit the letter electronically via jtcvs.editorialmanager.com. Letters commenting on an article published in the JTCVS will be considered if they are received within 6 weeks of the time the article was published. Authors of the article being commented on will be given an opportunity of offer a timely response ( 2 weeks) to the letter. Authors of letters will be notified that the letter has been received. Unpublished letters cannot be returned.
}

could be the nonuniform lesion depth and the absence of transmurality. Indeed, several perioperative details could contribute to this phenomenon: incomplete surface contact between the energy source and the left atrial tissue, a thick and fibrotic left atrial wall, and high cardiac output during ablation, causing loss of heat energy. ${ }^{3}$

Whether the observed clinical success was improved by the associated partial cardiac denervation, thereby overcoming the potential absence of transmurality, remains a matter of speculation. Indeed, reinnervation is a mechanism that has been suggested explain recurrence of $\mathrm{AF}$ after radiofrequency catheter ablation in the atrium in an animal model. ${ }^{4}$ In a recent study by Kangavari and associates, ${ }^{5}$ radiofrequency catheter ablation was followed by an elevation in nerve growth factor concentration in peripheral veins from days 1 to 3 after the procedure. The paracrine effect of this growth factor could explain nerve sprouting, reinnervation, and recurrence of AF during followup. A better understanding of this recent observation, as well as the design of new algorithms to circumvent these possible limitations (such as heat gradient), could enhance the long-term outcome of totally endoscopic procedures.

Bachar El Oumeiri, MD Alain Jean Poncelet, MD Gebrine El Khoury, MD Department of Cardio-Thoracic and Vascular Surgery

Cliniques Universitaires Saint-Luc $U C L$

Brussels, Belgium

\section{References}

1. Yilmaz A, Van Putte BP, Van Boven WJ. Completely thoracoscopic bilateral pulmonary vein isolation and left atrial appendage exclusion for atrial fibrillation. J Thorac Cardiovasc Surg. 2008;136: 521-2.

2. Prasad SM, Maniar HS, Camillo J, Schuessler RB, Boineau BP, Sundt TM, et al. The Cox maze III procedure for atrial fibrillation: long-term efficacy in patients undergoing lone versus concomitant procedures. J Thorac Cardiovasc Surg. 2003;126:1822-7.

3. Gaynor SL, Byrd GD, Diodato MD, Ishii Y, Lee AM, Prasad SM, et al. Microwave ablation for atrial fibrillation: dose-response curves in the cardioplegia-arrested and beating heart. Ann Thorac Surg. 2006;81:72-6.
4. Okuyama Y, Pak HN, Miyauchi Y, Liu YB, Chou CC, Hayashi H, et al. Nerve sprouting induced by radiofrequency catheter ablation in dogs. Heart Rhythm. 2004;1:712-7.

5. Kangavari S, Oh YS, Zhou S, Youn HJ, Lee MY, Jung WS, et al. Radiofrequency catheter ablation and nerve growth factor concentration in humans. Heart Rhythm. 2006;3:1150-5.

doi:10.1016/j.jtcvs.2008.09.079

\section{Reply to the Editor:}

The Cox maze III procedure remains the criterion standard for treatment of standalone atrial fibrillation (AF), as well as for $\mathrm{AF}$ with concomitant disorders; however, it has not gained widespread acceptance because of its invasive nature. ${ }^{1}$ The questions arise of whether all the lesions are necessary to cure $\mathrm{AF}$ and whether it is necessary to expose all patients with AF to such a complex operation. Electrophysiologic studies have already identified the critical role of initiating foci, situated mainly at the orifices of the pulmonary veins. ${ }^{2}$ There is evidence suggesting that ganglionated plexuses (GPs) play an important role in the initiation and maintenance of $\mathrm{AF}^{3}$ Adding GP ablation to pulmonary vein isolation (PVI) increases efficacy in elimination of $\mathrm{AF}^{4}$

The original cut-and-sew maze procedure has been abandoned in part because of these considerations and because less invasive methods of surgical treatment for standalone $\mathrm{AF}$ are being developed. PVI is performed by ablation of the left atrium at the entry site of the pulmonary veins, targeted autonomic denervation, and left atrial appendage amputation, resulting in electrical isolation.

The success rate with PVI alone theoretically could reach $90 \%$ for paroxysmal AF with normal atrial diameter, because most of the triggering foci are situated at the pulmonary vein ostia. In cases of persistent or long-standing $\mathrm{AF}$, the role of a dilated left atrium as the substrate factor and its interplay with the trigger is important. PVI alone cannot reach the ideal success rate of $90 \%$ in cases of associated valve disease or left ventricular impairment.

The ability of dry bipolar radiofrequency ablation to produce $100 \%$ 